\title{
Association of the MMP9 gene with childhood cedar pollen sensitization and pollinosis
}

\author{
Hiroki Inoue ${ }^{1}$, Yoichi Mashimo ${ }^{1}$, Makiko Funamizu ${ }^{1}$, Shuji Yonekura ${ }^{2}$, Shigetoshi Horiguchi ${ }^{2}$, Naoki Shimojo ${ }^{3}$, \\ Yoichi Kohno $^{3}$, Yoshitaka Okamoto ${ }^{2}$, Akira Hata ${ }^{1}$ and Yoichi Suzuki ${ }^{1}$
}

Matrix metalloproteinase 9 (MMP9) gene has been shown to be involved in the pathogenesis of allergic rhinitis (AR) and asthma. Previous studies suggested that single-nucleotide polymorphisms (SNPs) of the MMP9 gene conferred a risk for childhood asthma. However, whether the SNPs confer a risk for AR has not been previously investigated. The objective of this study was to investigate whether SNPs of the MMP9 gene are associated with risk of seasonal AR (pollinosis), perennial AR and allergen sensitization. A total of 670 school children were recruited in Japan and genotyped for functional polymorphism in the promoter (-1590C/T: rs3918242) and three amino-acid substitutions (R297Q: rs17576; P574R: rs2250889; R668Q: rs17577). Serum levels of total and specific IgE were determined. Disease status and other clinical characteristics of the subjects were investigated using a questionnaire. Associations between the MMP9 SNPs and both AR and serum IgE levels were evaluated. $-1590 \mathrm{C} / \mathrm{T}$ showed significant association with cedar pollinosis (corrected $P(P c o r)=0.039$ ). R668Q was in strong linkage disequilibrium (LD) with $-1590 \mathrm{C} / \mathrm{T}$ and showed significant association with cedar pollinosis $(P c o r=0.023)$ and serum cedar pollen-specific IgE level (Pcor=0.022). A haplotype associated with $-1590 \mathrm{~T}$ and $668 \mathrm{Q}$ showed a significant association with cedar pollinosis, orchard grass pollinosis and cedar pollen-specific IgE (Pcor $=0.0012, P c o r=0.0059$ and $P$ cor $=0.0041$, respectively). R297Q and P574R were in weak LD with the rest of the SNPs and did not show significant association with disease. Compared with wild-type MMP9 protein (279R-574P-668R), a variant enzyme (279R-574P-668Q) that showed association with pollinosis had lower activity. However, lower enzyme activity was not associated with disease risk because another variant (279Q-574R-668R) showed lower enzyme activity but was not associated with pollinosis. The -1590T allele and its corresponding haplotype was associated with higher promoter activity and with pollen-specific IgE levels and pollinosis, suggesting that $-1590 \mathrm{C} / \mathrm{T}$ may have more impact on sensitization and disease development than R668Q. Our results suggest that the MMP9 gene confers susceptibility to cedar pollinosis in Japanese children. The MMP9 gene may be associated with pollinosis through sensitization processes.

Journal of Human Genetics (2012) 57, 176-183; doi:10.1038/jhg.2011.148; published online 12 January 2012

Keywords: allergic rhinitis; association; cedar pollinosis; haplotype; matrix metalloproteinase; MMP9 gene; serum IgE; SNP

\section{INTRODUCTION}

The main symptoms of allergic rhinitis (AR) are nasal congestion caused by mucosal edema; runny nose caused by hypersecretion; and repetitive sneezing. Pollinosis is a seasonal type of AR caused by an allergic reaction to pollen. Japanese cedar pollen is the most common causative allergen for pollinosis in Japan. According to a recent study, the prevalence rates of AR and cedar pollinosis in 2006 were 27.2 and $8.0 \%$, respectively; both of which were higher than the rates in $1996 .{ }^{1}$

Matrix metalloproteinases (MMPs) are a family of enzymes that not only degrade the extracellular matrix but also mediate activation of other proteases and secretion of cytokines, thereby affecting inflammatory processes. ${ }^{2,3} \mathrm{MMP} 9$, also known as gelatinase $\mathrm{B}$, was shown to be an important mediator of inflammation in a murine model of asthma ${ }^{4,5}$ and in immune complex-mediated lung injury. ${ }^{6}$ In a mouse asthma model, loss of the MMP9 gene was found to inhibit the development of allergic inflammation by impairing the recruitment of dendritic cells (DCs) into the alveoli and the local production of proallergic chemokines by DCs. ${ }^{7}$ MMP9 levels in bronchoalveolar lavage and in the plasma are positively associated with allergen challenge $\mathrm{e}^{8}$ and severity of disease $\mathrm{e}^{9,10}$ in asthmatic patients, suggesting the involvement of MMP9 in asthma pathogenesis in humans. Compared with what is known about the role of MMP9 in asthma, knowledge regarding AR is limited. It has been demonstrated that nasal provocation with allergen induces release of MMP9 during the late-phase inflammatory response. ${ }^{11}$ Lim et al. ${ }^{12}$ reported that airway remodeling associated with long-term allergen challenge can occur in the nasal mucosa and the lung, and that expressions of MMP9 and tissue inhibitors of metalloproteinase 1 (Timp-1) were increased in

${ }^{1}$ Department of Public Health, Graduate School of Medicine, Chiba University, Chiba, Japan; ${ }^{2}$ Department of Otolaryngology, Graduate School of Medicine, Chiba University, Chiba, Japan and ${ }^{3}$ Department of Pediatrics, Graduate School of Medicine, Chiba University, Chiba, Japan

Correspondence: Professor Y Suzuki, Department of Public Health, Graduate School of Medicine, Chiba University, 1-8-1 Inohana, Chuo-ku, Chiba 260-8670, Japan.

E-mail: ysuzuki@faculty.chiba-u.jp

Received 6 August 2011; revised 3 December 2011; accepted 7 December 2011; published online 12 January 2012 
subepithelial regions. Shimizu et al. ${ }^{13}$ reported that the attenuating effect of tranilast on MMP9 production from nasal fibroblasts induced by inflammatory stimulation may underlie the therapeutic mode of action of this agent in patients with allergic diseases including AR.

The MMP9 gene is located at chromosome $20 \mathrm{q},{ }^{14}$ where linkage to bronchial hyperresponsiveness $^{15}$ and specific sensitization ${ }^{15,16}$ has been reported. In a previous association study of the MMP9 gene with asthma in the Japanese population, ${ }^{17}$ single-nucleotide polymorphisms (SNPs) 2127G/A (rs2274755) and 5546G/A (R668Q; rs17577), which were in strong linkage disequilibrium (LD), were shown to be significantly associated with atopic childhood asthma. The SNP 2127G/A was in complete LD with a promoter SNP ($1590 \mathrm{C} / \mathrm{T}, \mathrm{rs} 3918242$ ) in which the $\mathrm{T}$ allele showed higher promoter activity than the $\mathrm{C}$ allele in a promoter assay in a bronchial epithelial cell line. ${ }^{17}$ There are two more SNPs that change the amino-acid sequence of MMP9: R279Q (rs17576) and P574R (rs2250889). R279Q was shown to be associated with aortic pulse wave velocity and serum MMP9 level. ${ }^{18}$ However, the effects of these three amino-acid changes on enzyme activity or function at the molecular level have not been reported previously. To our knowledge, no studies have been conducted to investigate whether the MMP9 SNPs that showed association with asthma confer a risk for AR or allergic sensitization (atopy).

To investigate the association between the MMP9 gene and both AR and sensitization to common aero-allergens, we genotyped the functional promoter SNP and three potentially functional coding SNPs, and evaluated the symptoms of AR and serum total/specific IgE levels in Japanese school children. We also evaluated the effect of the aminoacid changes on MMP9 enzyme activity.

\section{MATERIALS AND METHODS}

\section{Subjects}

Japanese elementary school children in Chiba and Yamanashi prefectures were recruited for this study. A total of 473 school children aged 6-12 years were enrolled in Chiba city in Chiba prefecture, details of which were described previously, ${ }^{19}$ and 260 school children within the same age range were enrolled in Hokoto city in Yamanashi prefecture. Blood samples were collected for serum IgE measurement and DNA preparation from 410 children in Chiba and 260 children in Yamanashi in July and August 2006.

Total and specific serum IgE levels were assayed using the CAP-radioallergosorbent test (Pharmacia Diagnostics, Uppsala, Sweden). Eight specific IgEs were measured house dust mite (Dermatophagouides pteronyssinus), dog (Canis familiaris) dander, cat (Felis domesticus) dander, black mold (Alternaria alternata), cedar (Cryptomeria japonica) pollen, orchard grass (Dactylis glomerata), egg white, and golden, black bellied, or djungarian hamsters (Mesocricetus auratus/Cricetus cricetus/Phodopus sungorus). Atopy was defined as the presence of $\left(\geqslant 0.35 \mathrm{IU} \mathrm{ml}^{-1}\right)$ specific IgE positive against at least one of the assessed allergens. To assess the status of allergic diseases, questionnaires based on the International Study of Asthma and Allergies in Childhood ${ }^{20}$ were used. Subjects with symptoms of AR in any month from February to May and positive serum IgE to cedar pollen (class 1 and higher) were defined as having cedar pollinosis. Subjects with symptoms of AR in any month from May to July and positive serum IgE to orchard grass pollen were defined as having orchard grass pollinosis. Mite-positive perennial AR was diagnosed in children who had symptoms throughout the duration of a year and positive serum mite-specific IgE. Children who were negative for IgE specific to any assessed allergen and had no allergic diseases were assigned to the non-atopic control group. This study was approved by the ethics committee of Chiba University Graduate School of Medicine.

\section{SNP selection and genotyping}

In a previous association study by Nakashima et al., ${ }^{17}$ 2127G/A (rs2274755) and 5546G/A (R668Q: rs17577) showed significant association with asthma in Japanese children. We selected these as candidate SNPs for AR. In the same study, $-1590 \mathrm{C} / \mathrm{T}$ (rs3918242) was shown to be a functional SNP and in complete LD with 2127G/A in 24 individuals. This SNP, however, was not genotyped in all samples. In light of the importance of this SNP, we genotyped $-1590 \mathrm{C} / \mathrm{T}$ in the present study. We also included two non-synonymous SNPs, R279Q (rs17576) and P574R (rs2250889), because of their possible effect on enzyme activity and susceptibility to AR.

Genomic DNA was prepared from whole blood samples using a standard protocol. Whole genome amplification was performed using the illustra GenomiPhi V2 amplification kit (GE Healthcare, Buckinghamshire, UK) according to the manufacturer's standard protocol.

Genotyping was performed using the SNaPshot method (Applied Biosystems, Foster City, CA, USA). Multiplex PCR amplification was performed in a $10-\mu \mathrm{l}$ aliquot of reaction mixture containing $5 \mathrm{ng}$ amplified template DNA, 0.025 U TaKaRa ExTaq HS (TaKaRa Bio Inc., Otsu, Japan), $1 \mu 1$ 10× Ex buffer, $200 \mu \mathrm{m}$ of each dNTP and $0.5 \mu \mathrm{m}$ each of the PCR primer pairs shown in Supplementary Table 1. Amplification was carried out using a GeneAmp PCR System 9700 (Applied Biosystems) according to the following program: initial denaturation at $95^{\circ} \mathrm{C}$ for 3 min followed by 40 cycles at $95^{\circ} \mathrm{C}$ for $20 \mathrm{~s}, 60^{\circ} \mathrm{C}$ for $30 \mathrm{~s}$ and $72^{\circ} \mathrm{C}$ for $1 \mathrm{~min}$, with final extension at $72^{\circ} \mathrm{C}$ for $5 \mathrm{~min}$. Post-PCR treatment to remove primers and unincorporated dNTPs was performed with SAP (shrimp alkaline phosphatase; TaKaRa Bio Inc.) and ExoI (New England Biolabs, Ipswich, MA, USA). PCR products were incubated with $0.5 \mathrm{U}$ SAP and $1^{\prime} \mathrm{U}$ ExoI for $1 \mathrm{~h}$ at $37^{\circ} \mathrm{C}$, followed by incubation for $15 \mathrm{~min}$ at $80^{\circ} \mathrm{C}$ to induce enzyme inactivation. The $\mathrm{SNaPshot}$ reaction was performed in $10 \mu \mathrm{l}$ reaction mixture containing $0.5 \mu \mathrm{l} \mathrm{SNaPshot} \mathrm{Ready} \mathrm{Reaction} \mathrm{Mix,} 2 \mu \mathrm{l} \mathrm{SAP/ExoI-treated}$ PCR products and $0.1 \mu \mathrm{l}$ SNaPshot primers, as shown in Supplementary Table 1. SNaPshot primers were designed to anneal adjacent to the SNP of interest and to contain an additional sequence with several (incomplete) repeats of the "acgt" sequence (indicated by lower case) at the $5^{\prime}$-end to obtain a convenient length to discriminate it from other $\mathrm{SNaPshot}$ products. The reaction mixture was subjected to an initial step of $96^{\circ} \mathrm{C}$ for $1 \mathrm{~min}$ to activate the enzyme, followed by 35 single-base extension cycles of denaturation at $96^{\circ} \mathrm{C}$ for $10 \mathrm{~s}$ and annealing and extension at $60^{\circ} \mathrm{C}$ for $30 \mathrm{~s}$. Post-extension treatment to remove the $5^{\prime}$-phosphoryl group of the ddNTPs was performed with CIAP (calf intestine alkaline phosphatase; TaKaRa Bio Inc.). The final mixture $(6 \mu \mathrm{l})$ was treated with $1 \mathrm{U}$ CIAP for $60 \mathrm{~min}$ at $37^{\circ} \mathrm{C}$, followed by $15 \mathrm{~min}$ at $80^{\circ} \mathrm{C}$ for enzyme inactivation. The SNaPshot products $(1 \mu \mathrm{l})$ were mixed with $10 \mu \mathrm{liDi}$ formamide and $0.05 \mu \mathrm{l}$ GeneScan-120 LIZ size standard (Applied Biosystems) and electrophoresed using a 50-cm length capillary with Performance Optimum Polymer 6 (POP6) on an ABI PRISM 3100 Genetic Analyzer (Applied Biosystems). The resulting data were analyzed with GeneMapper v3.5 software (Applied Biosystems).

\section{Expression vector construction}

A cDNA fragment encoding human $M M P 9$ was obtained from normal human small airway epithelial cells using reverse transcriptase PCR and the following primers: forward, 5'-CCC AAG CTG GCT AGC GAC ACC TCT GCC CTC ACC ATG A-3'; reverse, $5^{\prime}$-CCC TCT AGA CTC GAG GTT GGT CCC AGT GGG GAT TTA-3' (both primers include the 15-bp homology extension for InFusion cloning into vector pcDNA3.1). The cDNA fragment was cloned into pcDNA3.1 (+) (Life Technologies, Carlsbad, CA, USA) and digested with NheIXhoI using the In-Fusion Advantage PCR Cloning Kit (TaKaRa Bio Inc.). The Q279R, R574P and R668Q mutations were introduced by PCR-based sitedirected mutagenesis using PrimeSTAR MAX polymerase (TaKaRa Bio Inc.). We constructed four MMP9 expression vectors containing four different haplotypes of MMP9: pcDNA3.1-MMP9-H1 (279R-574P-668R: type 1), pcDNA3.1-MMP9-H2 (279Q-574R-668R: type 2), pcDNA3.1-MMP9-H3 (279R-574P-668Q: type 3) and pcDNA3.1-MMP9-H4 (279Q-574R-668Q: type 4). The nucleotide sequences of $M M P 9$ in these constructs were confirmed by DNA sequencing before transfection of cells

\section{Stable transformants}

HEK293 (human embryonic kidney cell line) cells were cultured in minimum essential medium supplemented with $2 \mathrm{~mm}$ L-glutamine, $1 \%$ non-essential amino acids, 10\% fetal bovine serum and antibiotics. Empty vector pcDNA3.1 or MMP9 expression vectors pcDNA3.1-MMP9 were transfected into the cells 
using FuGENE6 transfection reagent (Roche Diagnostics, Basel, Switzerland) according to the manufacturer's instructions. Stable transformants were obtained after 2-3 weeks by selection with $600 \mu \mathrm{g} \mathrm{ml}^{-1}$ Geneticin (G-418).

\section{Enzyme activity}

Stable transformant cell lines were maintained with $10 \%$ fetal calf serum in minimum essential medium. For the enzyme assay, $5 \times 10^{6}$ cells were seeded in a $25-\mathrm{cm}^{2}$ flask with minimum essential medium without fetal calf serum. After $24 \mathrm{~h}$ of incubation at $37^{\circ} \mathrm{C}$, medium was recovered and stored at $-20^{\circ} \mathrm{C}$ until use. MMP9 proenzyme secreted into the culture medium was activated with $1 \mathrm{~mm}$ 4-aminophenylmercuric acetate before adding to the assay mixture. Protease activity of MMP9 in the conditioned medium was evaluated with synthetic fluorescence peptide as a substrate using SensoLyte 520 MMP9 Assay Kit fluorimetric (AanSpec Inc., Fremont, CA, USA). Fluorescence of 5-carboxyfluorescein was monitored at excitation/emission wavelengths of 490 and $520 \mathrm{~nm}$ using infinite F200 (TECAN, Männedorf, Switzerland). BioPlex 200 (Bio-Rad Laboratories, Hercules, CA, USA) was used to measure MMP9 protein concentrations in the medium with Fluorokine MAP assay kit (R\&D Systems, Inc., Minneapolis, MN, USA). Standard proteins included in the kit were used to calculate MMP9 protein concentration.

\section{Statistical analysis}

We used $r^{2}$ as an estimator of the strength of pairwise LD of SNPs. ${ }^{21}$ A $2 \times 2$ contingency $\chi^{2}$ test of independence was performed to test an association between genotypes and the disease in a dominant model. Haplotype inference was performed with an expectation-maximization algorithm implemented in SNPAlyze ver.4.1 (DYNACOM, Mobara, Japan). In single SNP association studies, significant values were corrected for number of SNPs and phenotypes tested (Bonferroni's correction). In the haplotype-wise test, significant values were corrected for multiple comparisons by multiplying the $P$-value by the number of haplotypes and phenotypes. The effects of genotypes on $\log _{10^{-}}$ transformed total serum IgE levels were evaluated using analysis of variance. Statistical analysis was performed with SPSS software (version 15.0J; SPSS Japan, Tokyo, Japan). Because the number of specific IgE values out of the detection limit $\left(0.34-100.0 \mathrm{U} \mathrm{ml}^{-1}\right)$ was not negligible, we conducted tobit regression analyses using the AER add-on package in $\mathrm{R}$ (http://www.r-project. org/) to evaluate the effect of SNPs on allergen-specific IgE values. Tobit regression analysis allows for modeling a continuous variable in which censored values at a specific value were not negligible. ${ }^{22} \mathrm{~A}$ corrected $P$ (Pcor)-value $<0.05$ was considered statistically significant.

\section{RESULTS}

Association between polymorphisms of the MMP9 gene and AR Basic characteristics of the children in this study are shown in Table 1. We measured total and specific serum IgE levels in 670 schoolchildren in Chiba and Yamanashi prefectures. Cedar pollinosis, orchard grass pollinosis and mite-positive perennial AR were diagnosed according to symptoms and serum IgE levels as described above. Of 54 children with orchard grass pollinosis, 48 also met the criteria for cedar pollinosis. A total of 104 children were found to have cedar-only pollinosis and six had orchard grass-only pollinosis. Children who showed no symptoms of AR, asthma, atopic dermatitis or food allergy and were negative for all measured specific IgE were included in the non-atopic control group. There was no difference in age and sex ratio between children with seasonal or perennial $\mathrm{AR}$ and the control group.

We genotyped five MMP9 SNPs in all subjects. The location of these SNPs is shown in Figure 1, with SNP and LD data from the HapMap database. $^{23}$ Three SNPs, -1590C/T (SNP1; rs3918242), 2127G/A (SNP2; rs2274755) and 5546G/A (SNP5; rs17577), were in strong LD and had previously been shown to be associated with childhood asthma. ${ }^{17}$ SNP5 is an amino-acid substitution, R668Q. SNP3 and SNP4 are also amino-acid substitutions (R297Q (SNP3; rs17576) and P574R (SNP4; rs2250889)). LD between SNP3 and SNP4 was strong $\left(r^{2}=0.711\right)$; however, these two SNPs had minimal LD with any of the other SNPs. All SNPs were in Hardy-Weinberg equilibrium in the case and control groups. Table 2 shows the genotype frequency of each polymorphism and association test results for the patients with AR and the non-atopic controls. Because SNP1 and SNP2 were in almost complete LD, the genotype results were almost the same. Both SNPs showed significant association with cedar and orchard grass pollinosis. In a dominant model (CC vs CT+TT), the odds ratio (OR) of SNP1 was 0.436 (95\% confidence interval $(\mathrm{CI})=0.252-0.752, P=0.0026$, Pcor $=0.039)$ for cedar pollinosis, and $0.234(95 \% \mathrm{CI}=0.097-0.566$, $P=0.00071, P c o r=0.011)$ for orchard grass pollinosis. ORs of SNP2 (GG vs GT+TT) were $0.419(95 \% \mathrm{CI}=0.242-0.726$, Pcor $=0.025)$ for cedar pollinosis and $0.234(95 \% \mathrm{CI}=0.097-0.566$, Pcor $=0.011)$ for orchard grass pollinosis. The ORs of SNP5 (GG vs GA+AA) for cedar pollinosis and orchard grass pollinosis were 0.430 (95\% CI $=0.255-$ 0.726$, Pcor $=0.023)$ and $0.241(95 \% \mathrm{CI}=0.107-0.541$, Pcor $=0.0049)$, respectively. Neither SNP3 nor SNP4 showed significant association with the two types of pollinosis.

ORs of SNP1 and SNP5 for the 48 patients with cedar and orchard grass pollinosis were $0.183(95 \% \mathrm{CI}=0.067-0.499$, Pcor $=0.0051)$ and 0.206 (95\% CI $=0.085-0.499$, Pcor $=0.0033)$, respectively. Diagnoses of cedar pollinosis and orchard grass pollinosis were significantly associated ( $\chi^{2}$ test, $P=1.29 \times 10^{-7}$ ).

The results of the association test between SNPs and mite-positive perennial AR are also shown in Table 2. Although raw $P$-values for SNP1 and SNP5 were $<0.05$, none of the SNPs showed significant association with the disease after correction for multiple testing. ORs of SNP1 and SNP5 for this type of AR were $0.484(95 \% \mathrm{CI}=0.228-$ $1.028, P=0.056)$ and $0.458(95 \% \mathrm{CI}=0.221-0.938, P=0.031)$, respectively. Among the 51 mite-positive perennial AR patients, $31(61 \%)$ also met the diagnostic criteria for cedar pollinosis. ORs of SNP1 and SNP5 for this group were $0.302(95 \% \mathrm{CI}=0.108-0.848, P=0.018)$ and 0.351 ( $95 \% \mathrm{CI}=0.140-0.884, P=0.023)$, respectively. ORs of SNP1 and SNP5 for mite-positive perennial AR-only patients were 0.848 (95\% $\mathrm{CI}=0.312-2.29, P=0.742)$ and $0.648 \quad(95 \% \mathrm{CI}=0.240-1.75$, $P=0.390)$, respectively. Diagnoses of cedar pollinosis and mite-positive perennial AR were not significantly associated ( $\chi^{2}$ test, $P=0.303$ ).

Table 1 Characteristics of the study population

\begin{tabular}{|c|c|c|c|c|c|c|}
\hline & $\begin{array}{l}\text { Whole study } \\
\text { population }\end{array}$ & $\begin{array}{c}\text { Cedar } \\
\text { pollinosis }\end{array}$ & $\begin{array}{c}\text { Orchard grass } \\
\text { pollinosis }\end{array}$ & $\begin{array}{l}\text { Mite-positive } \\
\text { perennial AR }\end{array}$ & $\begin{array}{c}\text { Non-atopic } \\
\text { control }\end{array}$ & Atopic ${ }^{\mathrm{a}}$ \\
\hline Number & 670 & 152 & 54 & 51 & 108 & 495 \\
\hline Age, mean (years) & 9.37 & 9.42 & 9.44 & 9.29 & 9.23 & 9.36 \\
\hline Age, range (years) & 6-12 & 6-12 & 6-12 & 6-12 & 6-12 & 6-12 \\
\hline Sex (male:female) & $1.06: 1.0$ & $1.41: 1.0$ & $2.6: 1.0$ & $1.83: 1.0$ & $1.0: 1.30$ & $1.0: 0.86$ \\
\hline Mean total $\lg E\left(\log \left(\mid \cup \mathrm{ml}^{-1}\right)\right)$ & 2.10 & 2.53 & 2.67 & 2.51 & 1.31 & 2.36 \\
\hline
\end{tabular}

Abbreviation: AR, allergic rhinitis.

apositive for at least one specific IgE, regardless of allergic disease status. 
$20 \mathrm{q} 13.12$

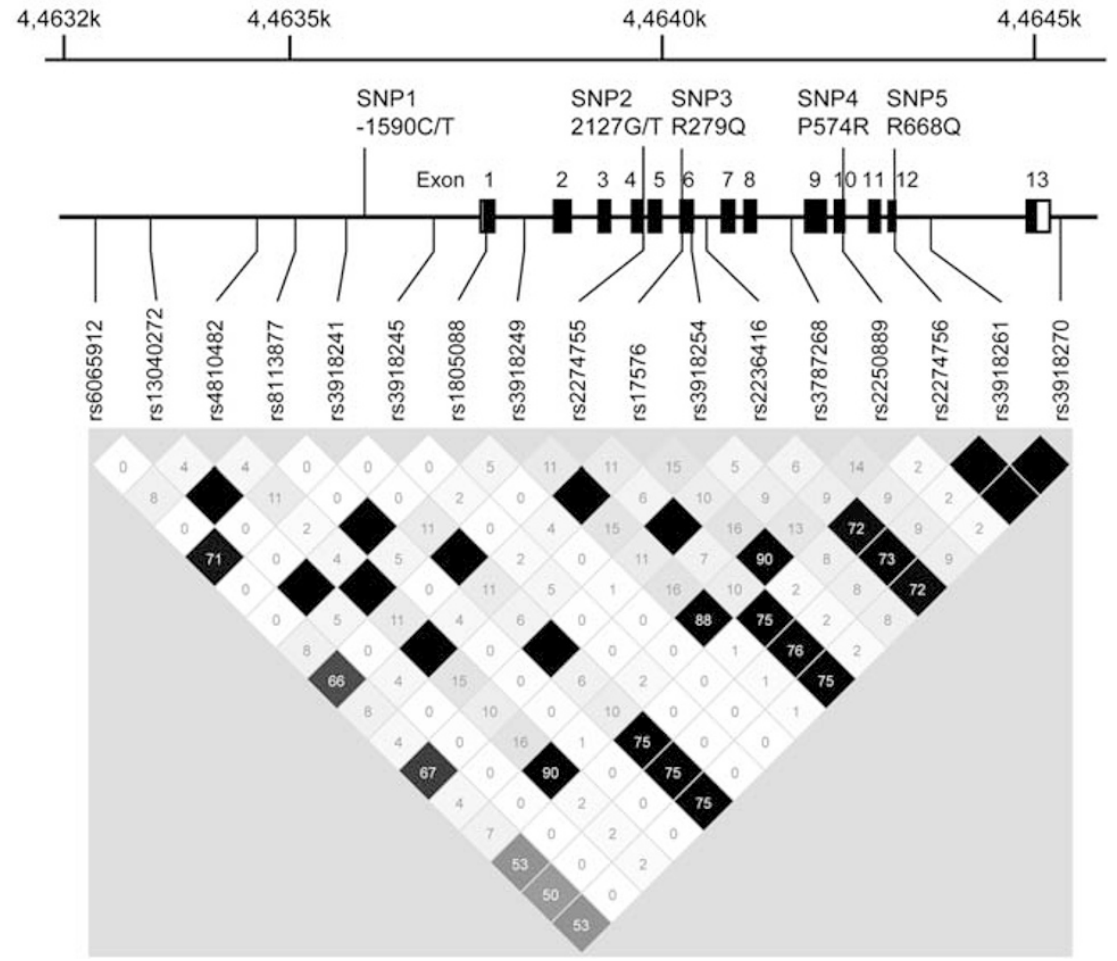

Figure 1 Structure and location of SNPS of the MMP9 gene. Exons are shown by squares. Filled squares are coding exons. Five SNPs genotyped in this study are shown above the gene map, and HapMap SNPs and their LD status are shown underneath. Data used for LD are based on Japanese data in HapMap data Phase III/Rel3, May 10 on NCBI B36 assembly, dbSNP b126. The nucleotide position is based on February 2009 (GRCh37/hg19) assembly. SNP1 was not found in HapMap database but was known to be in complete LD with rs2918241 and SNP2. ${ }^{17}$ Numbers in diamonds in the LD map are $r^{2} \times 100$.

Table 2 Association between SNPs of MMP9 and cedar pollinosis

\begin{tabular}{|c|c|c|c|c|c|c|c|c|c|c|c|c|c|c|c|}
\hline \multirow[b]{3}{*}{$S N P$} & \multicolumn{12}{|c|}{ Genotype frequency } & \multicolumn{3}{|c|}{ Pcor } \\
\hline & \multicolumn{3}{|c|}{ Cedar pollinosis } & \multicolumn{3}{|c|}{$\begin{array}{l}\text { Orchard grass } \\
\text { pollinosis }\end{array}$} & \multicolumn{3}{|c|}{$\begin{array}{l}\text { Mite-positive } \\
\text { perennial AR }\end{array}$} & \multicolumn{3}{|c|}{ Control } & \multirow{2}{*}{$\begin{array}{c}\text { Cedar } \\
\text { pollinosis vs } \\
\text { contro/ }\end{array}$} & \multirow{2}{*}{$\begin{array}{c}\text { Orchard grass } \\
\text { pollinosis vs } \\
\text { control }\end{array}$} & \multirow{2}{*}{$\begin{array}{c}\text { Mite-positive } \\
\text { perennial } \\
\text { AR vs contro }\end{array}$} \\
\hline & $11^{\mathrm{b}}$ & $12^{c}$ & $22^{\mathrm{d}}$ & $11^{\mathrm{b}}$ & $12^{x}$ & $22^{\mathrm{d}}$ & $11^{\mathrm{b}}$ & $12^{x}$ & $22^{\mathrm{d}}$ & $11^{\mathrm{b}}$ & $12^{x}$ & $22^{\mathrm{d}}$ & & & \\
\hline$-1590 \mathrm{C} / \mathrm{T}$ (SNP1) & 0.783 & 0.204 & 0.013 & 0.870 & 0.111 & 0.019 & 0.765 & 0.235 & 0.000 & 0.611 & 0.343 & 0.046 & 0.039 & 0.011 & 0.844 \\
\hline P574R (SNP4) & 0.520 & 0.408 & 0.072 & 0.574 & 0.333 & 0.093 & 0.608 & 0.333 & 0.059 & 0.556 & 0.417 & 0.028 & $>1$ & $>1$ & $>1$ \\
\hline R668Q (SNP5) & 0.737 & 0.237 & 0.026 & 0.833 & 0.130 & 0.037 & 0.725 & 0.275 & 0.000 & 0.546 & 0.398 & 0.056 & 0.023 & 0.0049 & 0.466 \\
\hline
\end{tabular}

Abbreviations: AR, allergic rhinitis; MMP9, matrix metalloproteinase 9; SNP, single-nucleotide polymorphism.

a $P$-values for association between an SNP and a phenotype in the dominant model. Pcor-values are calculated by multiplying raw $P$-value by 15 (that is, number of SNPs tested $\times$ number of diseases). 'Homozygous for major allele.

cHeterozygous.

dHomozygous for minor allele.

Significant Pcor-values $(<0.05)$ are in boldface.

Because the numbers of subjects with orchard grass pollinosis and mite-positive perennial AR were similar, the association of SNP1, SNP2 and SNP5 with mite-positive perennial AR may be weaker than that with orchard grass (with or without cedar) pollinosis.

\section{Association between SNPs and serum IgE levels}

In the analysis of serum IgE levels, all individuals were included, irrespective of the presence of atopy or disease status. We first examined the distribution of log-transformed total serum $\operatorname{IgE}$ $[\log ($ total $\operatorname{IgE})]$ in the 670 school children (data not shown). The rate of values lower than the cutoff was low and the shape of the distribution was almost normal; therefore, we evaluated the association between SNPs and $\log$ (total IgE) using analysis of variance. By contrast, because censored values were not negligible, we evaluated the association between SNPs and log-transformed specific IgE values with tobit regression analysis. The effects of SNPs on the IgE values were adjusted for age and sex, and the results of the tests are shown in Table 3. We excluded SNP2 from this analysis because it was thought to be a 
Table 3 Association between SNPs and serum IgE levels

\begin{tabular}{|c|c|c|c|c|c|c|c|c|c|c|c|c|c|c|}
\hline \multirow[b]{2}{*}{ SNP } & \multirow[b]{2}{*}{ Allele } & \multirow[b]{2}{*}{ Number of subjects } & \multicolumn{3}{|c|}{$\log ($ total $\lg E)$} & \multicolumn{3}{|c|}{$\log (c e d a r \lg E)$} & \multicolumn{3}{|c|}{ log(orchard grass lgE) } & \multicolumn{3}{|c|}{$\log ($ mite $\lg E)$} \\
\hline & & & Mean & s.d. & Pcor ${ }^{a}$ & Mean & s.d. & Pcor ${ }^{b}$ & Mean & s.d. & Pcor ${ }^{b}$ & Mean & s.d. & Pcor \\
\hline & $\mathrm{C} / \mathrm{T}+\mathrm{T} / \mathrm{T}$ & 199 & 2.04 & 0.67 & 0.517 & 0.23 & 0.90 & 0.066 & -0.25 & 0.49 & 0.613 & 0.34 & 0.98 & $>1$ \\
\hline \multirow[t]{2}{*}{ R279Q (SNP3) } & $\mathrm{R} / \mathrm{R}$ & 308 & 2.07 & 0.68 & & 0.42 & 0.98 & & -0.19 & 0.56 & & 0.41 & 0.99 & \\
\hline & $R / Q+Q / Q$ & 359 & 2.12 & 0.68 & 0.737 & 0.33 & 0.90 & $>1$ & -0.17 & 0.59 & $>1$ & 0.46 & 1.03 & $>1$ \\
\hline \multirow[t]{2}{*}{ R668Q (SNP5) } & $\mathrm{R} / \mathrm{R}$ & 439 & 2.14 & 0.68 & & 0.45 & 0.95 & & -0.14 & 0.61 & & 0.48 & 1.02 & \\
\hline & $R / Q+Q / Q$ & 231 & 2.03 & 0.67 & 0.173 & 0.22 & 0.90 & 0.022 & -0.26 & 0.48 & 0.257 & 0.36 & 0.99 & $>1$ \\
\hline
\end{tabular}

Abbreviation: SNP, single-nucleotide polymorphism.

aRaw $P$-values of coefficients of SNPs for log-transformed total IgE value are calculated as a general linear model with age and sex as covariates. $P$ cor-values are calculated by multiplying raw $P$-values by 16 (that is, number of SNPs tested $\times$ number of IgE values).

bRaw $P$-values of coefficients of SNPs for log-transformed specific IgE values are calculated using a tobit regression model with age and sex as covariates. $P$ cor-values are calculated by multiplying raw $P$ tobit values by 16 (that is, number of SNPs tested $\times$ number of IgE values).

Significant $P$ cor-values $(<0.05)$ are in boldface.

Table 4 Association between haplotype and allergic rhinitis (RA)

\begin{tabular}{|c|c|c|c|c|c|c|c|c|}
\hline \multirow[b]{2}{*}{ Haplotype } & \multirow[b]{2}{*}{ SNP1-5 } & \multicolumn{3}{|c|}{ Frequency } & \multirow[b]{2}{*}{ Control } & \multicolumn{3}{|c|}{ Pcora } \\
\hline & & $\begin{array}{c}\text { Cedar } \\
\text { pollinosis }\end{array}$ & $\begin{array}{c}\text { Orchard grass } \\
\text { pollinosis }\end{array}$ & $\begin{array}{l}\text { Mite-positive } \\
\text { perennial } A R\end{array}$ & & $\begin{array}{l}\text { Cedar pollinosis } \\
\text { vs control }\end{array}$ & $\begin{array}{c}\text { Orchard grass pollinosis } \\
\text { vs control }\end{array}$ & $\begin{array}{c}\text { Mite-positive perennial } \\
\text { AR vs control }\end{array}$ \\
\hline Haplotype 1 & CGGCG & 0.566 & 0.612 & 0.575 & 0.510 & $>1$ & $>1$ & $>1$ \\
\hline Haplotype 2 & CGAGG & 0.254 & 0.225 & 0.217 & 0.214 & $>1$ & $>1$ & $>1$ \\
\hline Haplotype 3 & TTGCA & 0.107 & 0.071 & 0.120 & 0.230 & 0.0012 & 0.0059 & 0.201 \\
\hline Haplotype 4 & CGACG & 0.074 & 0.092 & 0.088 & 0.046 & $>1$ & $>1$ & $>1$ \\
\hline
\end{tabular}

Abbreviations: AR, allergic rhinitis; SNP, single-nucleotide polymorphism.

aRaw $P$-values are multiplied by 12 (that is, number of haplotypes $\times$ number of diseases).

Significant $P$ cor-values $(<0.05)$ are in boldface.

marker of functional SNP1 and almost the same results were expected. The lowest $P$-value for $\log$ (total IgE), 0.043, was observed for SNP5 and was not significant if the value was corrected by the number of SNPs. SNP5 was significantly associated with cedar pollen-specific IgE $($ Pcor $=0.022)$. Although SNP1 had a raw $P$-value of 0.0041 , the value was $>0.05$ after a multiple-test correction. A similar tendency was observed with regard to the association of these SNPs with orchard grass-specific IgE. The raw $P$-values for these SNPs were slightly $<0.05$ and did not reach the significance level after correction. None of the SNPs showed significant association with mite-specific IgE.

\section{Association of haplotype with AR and serum IgE levels}

The estimated frequencies of haplotypes consisting of SNP1 to SNP5 are shown in Table 4 . The frequency of the TTCGA haplotype [haplotype 3 (H3)] between cedar (10.7\%) and orchard grass (7.1\%) of childhood AR was significantly lower than that in child controls $(23.0 \%)$ (Pcor $=0.0012$ and Pcor $=0.0059$, respectively). This haplotype was not significantly associated with mite-positive perennial AR (Pcor=0.201). $\mathrm{H} 3$ consists of minor alleles of SNP1, SNP2 and SNP5, whereas other haplotypes [haplotype $1(\mathrm{H} 1)$, haplotype $2(\mathrm{H} 2)$ and haplotype $4(\mathrm{H} 4)$ ] correspond to the major allele of SNP1, SNP2 and SNP5 (CGXXG, X: any allele of SNP3/SNP4). Because the test of association was performed with $\mathrm{H} 3$ vs $\mathrm{H} 1+\mathrm{H} 2+\mathrm{H} 4$, the result is equivalent to the association between single SNP of SNP1, SNP2 or SNP5 and disease. The frequency of $\mathrm{H} 1, \mathrm{H} 2$ and $\mathrm{H} 4$ was higher in all three types of AR patient groups than in the control group. Association test of these haplotypes with the diseases, however, did not reach the level of significance. CGXXG-type haplotypes were equally divided into $\mathrm{H} 1, \mathrm{H} 2$ and $\mathrm{H} 4$ in all AR groups and in the control group by SNP3-SNP4 alleles that were not in LD with SNP1-SNP2-SNP5 and not associated with any diseases. This reduced the power to detect an association between each haplotype ( $\mathrm{H} 1, \mathrm{H} 2$ or $\mathrm{H} 4)$ and the disease type.

Next, we determined whether $\mathrm{H} 3$ has an impact on serum total and specific IgE levels (Table 5). Individuals with at least one $\mathrm{H} 3$ allele showed significantly lower cedar-specific IgE levels (Pcor=0.0041). The Pcor-value for the association with orchard grass-specific IgE was slightly $>0.05$. This suggests that individuals with $\mathrm{H} 3$ are less prone to pollen sensitization. No effect of $\mathrm{H} 3$ on total IgE level and mitespecific IgE level was evident.

\section{Effect of amino-acid changes on MMP9 activity}

Different promoter activities of alleles of SNP1 were reported previously. ${ }^{17}$ However, it was unknown whether the amino-acid change of SNP5 has any effect on MMP9 activity or function. To evaluate the effect of SNP5, we constructed four different MMP9 proteins composed of different combination of SNP3, SNP4 and SNP5 alleles because SNP3 and SNP4 may influence the effect of SNP5 on the enzyme activity.

As shown in Figure 2, type 1 enzyme showed significantly higher proteolytic activity than any of the other types of enzyme tested. Because $\mathrm{H} 1$ corresponds to type 1 enzyme and did not show significant association with pollinosis, a difference in enzyme activity 
Table 5 Association between haplotype 3 and serum IgE levels

\begin{tabular}{|c|c|c|c|c|c|c|c|c|c|c|c|c|c|}
\hline & \multirow[b]{2}{*}{ Number of subjects } & \multicolumn{3}{|c|}{$\log ($ total lgE) } & \multicolumn{3}{|c|}{$\log ($ cedar $\lg E)$} & \multicolumn{3}{|c|}{ log(orchard grass IgE) } & \multicolumn{3}{|c|}{$\log ($ mite $\lg E)$} \\
\hline & & Mean & s.d. & Pcor ${ }^{\mathrm{a}}$ & Mean & s.d. & $P c o r b$ & Mean & s.d. & Pcorb & Mean & s.d. & Pcor $r^{b}$ \\
\hline \multicolumn{14}{|l|}{ Haplotype 3} \\
\hline H3/H3+H3/others & 194 & 2.03 & 0.67 & & 0.21 & 0.89 & & -0.26 & 0.49 & & 0.33 & 0.97 & \\
\hline \multicolumn{14}{|l|}{ (H3) } \\
\hline
\end{tabular}

${ }^{a} P$-values of coefficients of haplotype 3 (H3) for log-transformed total lgE value are calculated as a general linear model with age and sex as covariates. $P$ cor-values are calculated by multiplying raw $P$-values by 4 (that is, number of IgE values).

b $P$-values of coefficients of $\mathrm{H} 3$ for log-transformed specific IgE values are calculated using a tobit regression model with age and sex as covariates. Pcor-values are calculated by multiplying raw

$P$-values by 4 (that is, number of IgE values).

Significant Pcor-values $(<0.05)$ are in boldface.

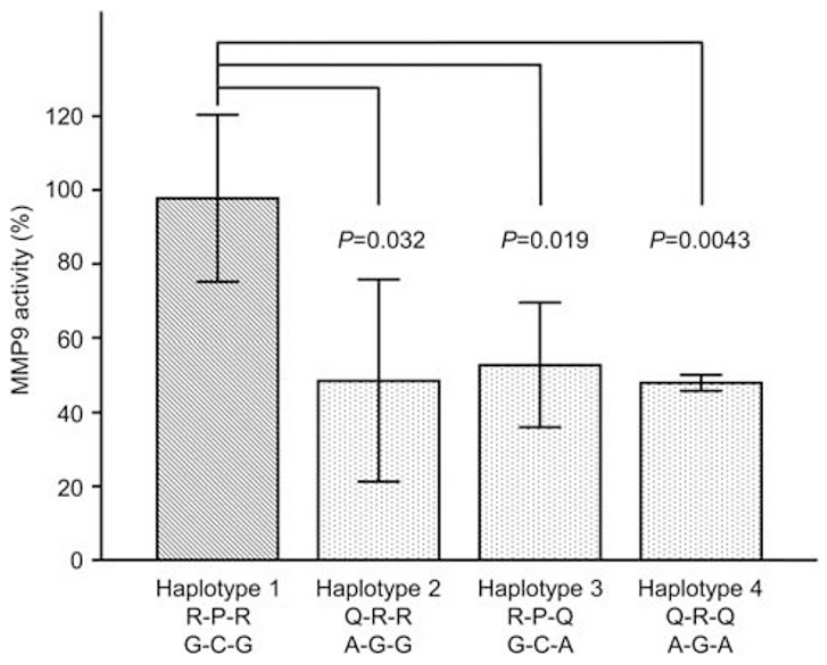

Figure 2 Comparison of peptide cleavage activity of different sequences of MMP9. MMP9 activity for peptide cleavage was monitored by 5carboxyfluorescein fluorescence. In each experiment, duplicate samples of cell culture medium were assayed. The activity of wild-type enzyme was set to $100 \%$ in each experiment. Values are expressed as mean and standard deviation of three independent experiments. Significance was evaluated using analysis of variance test.

was not associated with risk for pollinosis development in a straightforward manner. Compared with the type 1 (wild-type) enzyme, the amino-acid changes from R to Q at SNP5 (type 3) decreased enzyme activity by half $(P=0.019)$. The amino-acid change of $279 \mathrm{R}(\mathrm{SNP} 3)+$ $574 \mathrm{R}$ (SNP4) (type 2$)$ also decreased the activity $(P=0.032)$ to a similar extent. The activity of type 4 was similar to that of type 2 and type 3 , suggesting no additive effect by type 2 and type 3 amino-acid changes. SNP5 showed an association with cedar pollen sensitization and pollinosis and had an impact on MMP9 enzyme activity. However, a reduction in enzyme activity was also observed with SNP3 and SNP4, neither of which showed an association with disease. Thus, reduced activity was not enough to show an association with clinical phenotypes.

\section{DISCUSSION}

In this study, we investigated the association between (potentially) functional sequence variations of the MMP9 gene and AR in Japanese children. The SNPs $-1590 \mathrm{C} / \mathrm{T}$ (SNP1) and R668Q (SNP5) were in strong LD and were significantly associated with cedar and orchard grass pollinosis. SNP5 was also significantly associated with cedar pollen sensitization. To evaluate the pathological importance of SNP5, we measured the proteolytic activity of different types of MMP9 due to SNP3, SNP4 and SNP5. To our knowledge, the present study is the first to experimentally evaluate the effects of amino-acid changes in MMP9 on its proteolytic activity. Compared with the wildtype enzyme, enzymes with any tested combination of amino-acid substitution showed lower enzyme activity. However, lower enzyme activity and disease risk were not exactly correlated. As seen in Table 3, frequencies of $\mathrm{H} 1$ that correspond to the wild-type enzyme in the disease groups were higher than in the control group. It is possible that $\mathrm{H} 1$ is associated with higher risk for pollinosis, but this was not statistically significant. H3 was significantly associated with lower risk for pollinosis and is the only haplotype that contains the $\mathrm{T}$ allele of SNP1, which was shown previously to have higher promoter activity. ${ }^{17,24}$ From these observations, we speculate that different promoter activity associated with SNP1 may be more necessary or important for change in pollinosis risk than different enzyme activity associated with SNP5.

Although we observed significant associations between orchard grass pollinosis and both SNP1 and SNP5, this finding should be interpreted with caution because $89 \%$ (48/54) of orchard grass pollinosis patients also had cedar pollinosis. We could not test an association between the SNPs and genuine orchard grass pollinosis because only six children showed orchard grass-only pollinosis. In this test, we found an association between SNPs and pollinosis in patients with sensitization for two different pollens and longer duration of symptoms. Lower OR values and more significant $P$-values found in these patients compared with cedar pollinosis-only patients suggest that children with MMP9 susceptible allele tend to show a more severe phenotype: sensitization for more pollen types and longer duration of symptoms.

Patients with perennial AR with positive mite IgE did not show significant association with MMP9 SNPs. ORs of SNP1 and SNP5 of those children who also had pollinosis were a little lower than in the entire group, but were higher than in patients with both cedar and orchard grass pollinosis. Further, ORs in mite-positive perennial AR-only patients were similar to those in control children. The relationship between cedar pollinosis and mite-positive perennial AR was not significant. These results suggest a different pathogenesis for pollinosis and mite-positive perennial AR; in addition, MMP9 may have a more important role in the pathogenesis of cedar sensitization and pollinosis than in that of mite sensitization and mite-positive perennial AR.

A strong association between MMP9 gene variation and serum pollen-specific IgE levels suggests that MMP9 may be involved in the 
sensitization process for pollen in the upper airways. Several studies have investigated the role of MMP9 in the immune system. Ichiyasu et al. ${ }^{25}$ reported that DCs of the bone marrow from MMP9-deficient mice may have impaired migration through the tight junctions. Yen et $a .^{26}$ reported that DCs matured within inflammatory sites require both chemokine receptor type 7 and prostaglandin E2-induced MMP9 for directional migration to draining lymph nodes. Hintzen et al. ${ }^{27}$ reported that continuous DC-mediated transport of inhaled antigen to the bronchial lymph node is critical for the induction of tolerance to innocuous antigens. The roles of MMP9 are not restricted to DC migration. MMP9 was also reported to be involved in transmigration of lymphocyte, ${ }^{28}$ neutrophils ${ }^{28}$ and eosinophils. ${ }^{29}$ Recent results demonstrated that tissue-type plasminogen activator promoted several types of bone marrow cells to move to tissue remodeling sites and that MMP9 had a key role on this process by promoting Kit-ligand secretion and vascular endothelial growth factor A (VEGF-A) tissue store release. ${ }^{30}$ Furthermore, MMP9 is also known to be expressed in airway epithelial and subepithelial cells. ${ }^{31,32}$ These results suggest multipotent effects of MMP9 in the immune system and on tissue remodeling. The results of our association studies, and of many other studies, suggest that MMP9 is involved in the sensitization processes, in particular through migration of DCs and other cell types.

The T allele of SNP1 has been shown to have higher promoter activity, ${ }^{17}$ whereas enzyme activity associated with $\mathrm{H} 3$ was lower than H1 enzyme. Thus, the association between MMP9 expression/activity and risk for disease development appears to be complex. Because SNP1 and SNP5 are in strong LD and associated with cedar and orchard grass pollinosis to a similar extent, we cannot determine conclusively from the present results which of the SNPs is more important for disease development. As noted above, MMP9 is essential for the action of a variety of cell types, and some of these actions may antagonize in vivo biologic an immunologic processes such as IgE production, inflammation and tissue remodeling. Even in the standard allergic asthma model of $M m p 9$ knockout mice, totally discrepant results have been reported. ${ }^{4,5}$ It is therefore possible that subtle differences in environmental or genetic backgrounds are responsible for the changes in MMP9 expression/activity. Dissection of the mechanistic link between MMP9 variations and predisposition to sensitization or disease risk is very difficult at present.

A recent large cohort study in Germany investigating MMP9 SNPs and asthma development showed an association between Q279R and "non-atopic" asthma. ${ }^{33}$ This result is somewhat different from our observation that MMP9 SNPs were involved in pollen sensitization, suggesting that MMP9 may be involved in chronic airway inflammation processes through a mechanism other than sensitization. The different results may be due to the fact that cedar pollen is not a prevalent allergen in Germany and the larger statistical power of the study may reveal different roles of MMP9. Different patterns of association between SNPs and phenotypes may be reflected by the multifaceted nature of $M M P 9$ and its complex interactions with other genes and factors. ${ }^{34}$ Genotype-phonotype association studies under different environmental conditions may shed light on different functions of the MMP9 gene.

Currently, data on the relevance of MMP9 to nasal tissue pathogenesis in humans are limited. Lee et al. ${ }^{35}$ examined nasal polyp tissues from asthma patients and showed that the MMP9 level was correlated with the level of inflammatory cell markers such as eosinophilic cationic protein and tryptase. The expression of MMP9 mRNA was higher in nasal polyps when compared with inferior turbinate mucosa in patients with chronic rhinosinusitis. ${ }^{36}$ Wang et al. ${ }^{37}$ reported that 1590C/T and R668Q were associated with chronic rhinosinusitis with nasal polyposis. The haplotype corresponding to $\mathrm{H} 3$ in our study was also associated with the disease $(P=0.0045)$. However, negative results have also been reported. ${ }^{38}$ Biopsy specimens of nasal mucosa were taken from patients with perennial AR and nonrhinitic control subjects. MMP1, 2, 3 and 9 mRNA were measured and no upregulation of MMPs was found in the tissue from patients. MMP9 in nasal tissue in animals has also been studied. Lim et al. ${ }^{12}$ investigated upper- and lower-airway remodeling in murine model. OVA (ovalbumin)-sensitized mice were repeatedly exposed to inhalation of OVA for 1 month or 3 months. Repetitive OVA challenge for 3 months induced circumferential peribronchial fibrosis in the lung. Subepithelial fibrosis, increased MMP9 and Timp-1 expression, goblet cell hyperplasia and submucosal grand hypertrophy were observed in the nose. These findings are important because nasal mucosa may show similar pathologic changes to lung tissue and the MMP9 gene may have a significant role in the pathogenesis of nasal mucosa.

The present results support an important role of the MMP9 gene in pollen sensitization and pollinosis in Japanese children. Identifying the role of the MMP9 gene in the sensitization process in upper-airway tissues is of importance to understand the development of pollinosis. In addition, whether stimulation or inhibition of MMP9 activity may benefit treatment of AR is of interest.

\section{ACKNOWLEDGEMENTS}

We thank all patients and their families, the volunteers who served as controls, and all members of staff of hospitals involved in this study. We are also grateful for the excellent technical assistance of Mieko Yoshida and Yoshiko Hotta. This work was supported by Grants-in-Aid for Scientific Research from the Ministry of Education, Culture, Sports, Science and Technology, Japan, and grants from the Ministry of Health, Labor, and Welfare, Japan.

1 Kusunoki, T., Morimoto, T., Nishikomori, R., Yasumi, T., Heike, T., Fujii, T. et al. Changing prevalence and severity of childhood allergic diseases in Kyoto, Japan, from 1996 to 2006. Allergol. Int. 58, 543-548 (2009).

2 Nagase, H. \& Woessner Jr, J. F. Matrix metalloproteinases. J. Biol. Chem. 274, $21491-$ 21494 (1999)

3 Parks, W. C., Wilson, C. L. \& Lopez-Boado, Y. S. Matrix metalloproteinases as modulators of inflammation and innate immunity. Nat. Rev. Immunol. 4, 617-629 (2004).

4 McMillan, S. J., Kearley, J., Campbell, J. D., Zhu, X. W., Larbi, K. Y., Shipley, J. M. et al. Matrix metalloproteinase- 9 deficiency results in enhanced allergen-induced airway inflammation. J. Immunol. 172, 2586-2594 (2004).

5 Cataldo, D. D., Tournoy, K. G., Vermaelen, K., Munaut, C., Foidart, J. M., Louis, R. et al. Matrix metalloproteinase-9 deficiency impairs cellular infiltration and bronchial hyperresponsiveness during allergen-induced airway inflammation. Am. J. Pathol. 161, 491-498 (2002)

6 Atkinson, J. J. \& Senior, R. M. Matrix metalloproteinase-9 in lung remodeling. Am. J. Respir. Cell Mol. Biol. 28, 12-24 (2003).

7 Vermaelen, K. Y., Cataldo, D., Tournoy, K., Maes, T., Dhulst, A., Louis, R. et al. Matrix metalloproteinase-9-mediated dendritic cell recruitment into the airways is a critical step in a mouse model of asthma. J. Immunol. 171, 1016-1022 (2003).

8 Kelly, E. A., Busse, W. W. \& Jarjour, N. N. Increased matrix metalloproteinase-9 in the airway after allergen challenge. Am. J. Respir. Crit. Care Med. 162, 1157-1161 (2000).

9 Mattos, W., Lim, S., Russell, R., Jatakanon, A., Chung, K. F. \& Barnes, P. J. Matrix metalloproteinase-9 expression in asthma: effect of asthma severity, allergen challenge, and inhaled corticosteroids. Chest 122, 1543-1552 (2002).

10 Belleguic, C., Corbel, M., Germain, N., Lena, H., Boichot, E., Delaval, P. H. et al. Increased release of matrix metalloproteinase-9 in the plasma of acute severe asthmatic patients. Clin. Exp. Allergy 32, 217-223 (2002).

11 van Toorenenbergen, A. W., Gerth van Wijk, R. \& Vermeulen, A. M. Allergen-induced matrix metalloproteinase-9 in nasal lavage fluid. Allergy 54, 293-294 (1999).

12 Lim, Y. S., Won, T. B., Shim, W. S., Kim, Y. M. Kim, J. W., Lee, C. H. et al. Induction of airway remodeling of nasal mucosa by repetitive allergen challenge in a murine model of allergic rhinitis. Ann. Allergy Asthma Immunol. 98, 22-31 (2007).

13 Shimizu, T., Kanai, K., Asano, K., Hisamitsu, T. \& Suzaki, H. Suppression of matrix metalloproteinase production in nasal fibroblasts by tranilast, an antiallergic agent, in vitro. Mediators Inflamm. 2005, 150-159 (2005). 
14 Zhang, B., Henney, A., Eriksson, P., Hamsten, A., Watkins, H. \& Ye, S. Genetic variation at the matrix metalloproteinase-9 locus on chromosome 20q12.2-13.1. Hum. Genet. 105, 418-423 (1999)

15 Daniels, S. E., Bhattacharrya, S., James, A., Leaves, N. I., Young, A., Hill, M. R. et al. A genome-wide search for quantitative trait loci underlying asthma. Nature 383, 247-250 (1996).

16 Wjst, M. Specific IgE-one gene fits all? German Asthma Genetics Group. Clin. Exp. Allergy 29(Suppl 4), 5-10 (1999).

17 Nakashima, K., Hirota, T., Obara, K., Shimizu, M., Doi, S., Fujita, K. et al. A functional polymorphism in MMP-9 is associated with childhood atopic asthma. Biochem. Biophys. Res. Commun. 344, 300-307 (2006).

18 Yasmin, McEniery, C. M., O'Shaughnessy, K. M., Harnett, P., Arshad, A., Wallace, S. et al. Variation in the human matrix metalloproteinase- 9 gene is associated with arterial stiffness in healthy individuals. Arterioscler. Thromb. Vasc. Biol. 26, 1799-1805 (2006).

19 Suzuki, Y., Hattori, S., Mashimo, Y., Funamizu, M., Kohno, Y., Okamoto, Y. et al. CD14 and IL4R gene polymorphisms modify the effect of day care attendance on serum IgE levels. J. Allergy Clin. Immunol. 123, 1408-1411 e1401 (2009).

20 Asher, M. I., Keil, U., Anderson, H. R., Beasley, R., Crane, J., Martinez, F. et al. International Study of Asthma and Allergies in Childhood (ISAAC): rationale and methods. Eur. Respir. J. 8, 483-491 (1995).

21 Hill, W. G. \& Robertson, A. Linkage disequilibrium in finite populations. Theor. Appl. Genet. 38, 226-231 (1968).

22 Lubin, J. H., Colt, J. S., Camann, D., Davis, S., Cerhan, J. R., Severson, R. K. et al. Epidemiologic evaluation of measurement data in the presence of detection limits. Environ. Health Perspect. 112, 1691-1696 (2004).

23 Consortium, I. H. The International HapMap Project. Nature 426, 789-796 (2003).

24 Zhang, B., Ye, S., Herrmann, S. M., Eriksson, P., de Maat, M., Evans, A. et al. Functional polymorphism in the regulatory region of gelatinase $B$ gene in relation to severity of coronary atherosclerosis. Circulation 99, 1788-1794 (1999).

25 Ichiyasu, H., McCormack, J. M., McCarthy, K. M., Dombkowski, D., Preffer, F. I. \& Schneeberger, E. E. Matrix metalloproteinase-9-deficient dendritic cells have impaired migration through tracheal epithelial tight junctions. Am. J. Respir. Cell Mol. Biol. 30, 761-770 (2004).

26 Yen, J. H., Khayrullina, T. \& Ganea, D. PGE2-induced metalloproteinase-9 is essential for dendritic cell migration. Blood 111, 260-270 (2008).

27 Hintzen, G., Ohl, L., del Rio, M. L., Rodriguez-Barbosa, J. I., Pabst, O., Kocks, J. R. et al. Induction of tolerance to innocuous inhaled antigen relies on a CCR7-dependent dendritic cell-mediated antigen transport to the bronchial lymph node. J. Immunol. 177, 7346-7354 (2006)

28 Leppert, D., Waubant, E., Galardy, R., Bunnett, N. W. \& Hauser, S. L. T cell gelatinases mediate basement membrane transmigration in vitro. J. Immunol. 154, 4379-4389 (1995).

29 Okada, S., Kita, H., George, T. J., Gleich, G. J. \& Leiferman, K. M. Migration of eosinophils through basement membrane components in vitro: role of matrix metalloproteinase-9. Am. J. Respir. Cell Mol. Biol. 17, 519-528 (1997).

30 Ohki, M., Ohki, Y., Ishihara, M., Nishida, C., Tashiro, Y., Akiyama, H. et al. Tissue type plasminogen activator regulates myeloid-cell dependent neoangiogenesis during tissue regeneration. Blood 115, 4302-4312 (2010).

31 Wenzel, S. E., Balzar, S., Cundall, M. \& Chu, H. W. Subepithelial basement membrane immunoreactivity for matrix metalloproteinase 9: association with asthma severity, neutrophilic inflammation, and wound repair. J. Allergy Clin. Immunol. 111, 1345-1352 (2003).

32 Ritter, M., Mennerich, D., Weith, A. \& Seither, P. Characterization of Toll-like receptors in primary lung epithelial cells: strong impact of the TLR3 ligand poly $(I: C)$ on the regulation of Toll-like receptors, adaptor proteins and inflammatory response. J. Inflamm. (Lond) 2, 16 (2005).

33 Pinto, L. A., Depner, M., Klopp, N., Illig, T., Vogelberg, C., von Mutius, E. et al. MMP-9 gene variants increase the risk for non-atopic asthma in children. Respir. Res. 11, 23 (2010).

34 Greenlee, K. J., Werb, Z. \& Kheradmand, F. Matrix metalloproteinases in lung: multiple, multifarious, and multifaceted. Physiol. Rev. 87, 69-98 (2007).

35 Lee, Y. M., Kim, S. S., Kim, H. A., Suh, Y. J., Lee, S. K., Nahm, D. H. et al. Eosinophil inflammation of nasal polyp tissue: relationships with matrix metalloproteinases, tissue inhibitor of metalloproteinase-1, and transforming growth factor-beta1. J. Korean Med. Sci. 18, 97-102 (2003)

36 Chen, Y. S., Langhammer, T., Westhofen, M. \& Lorenzen, J. Relationship between matrix metalloproteinases MMP-2, MMP-9, tissue inhibitor of matrix metalloproteinases-1 and IL-5, IL-8 in nasal polyps. Allergy 62, 66-72 (2007).

37 Wang, L. F., Chien, C. Y., Tai, C. F., Kuo, W. R., His, E. \& Juo, S. H. Matrix metalloproteinase-9 gene polymorphisms in nasal polyposis. BMC Med. Genet. 11, 85 (2010).

38 Shaida, A., Kenyon, G., Devalia, J., Davies, R. J., MacDonald, T. T. \& Pender, S. L. Matrix metalloproteinases and their inhibitors in the nasal mucosa of patients with perennial allergic rhinitis. J. Allergy Clin. Immunol. 108, 791-796 (2001).

Supplementary Information accompanies the paper on Journal of Human Genetics website (http://www.nature.com/jhg) 